\title{
7. Whither Pacific 'traditional' media? Internet technology in political education and participation
}

\section{ABBSIRACI}

'Digital Democracy' and 'digital government' are relatively new concepts posing challenges for governments, journalists, political analysts and political scientists. Written from a political science perspective, this article provides an overview of selected Pacific Island government efforts on the web and assesses the contribution this makes to political education, on one level, and building egalitarian democracies on another level. Providing a brief survey of internet developments in the area of government within 12 selected Pacific Island countries, ${ }^{1}$ the argument is made that, while any additional education in the broad area of politics is welcome, there are still challenges that exist and room for progress. Given current technological capabilities around the region, more 'traditional' forms of media still have a vital role to play.

\section{KYLIE ANDERSON \\ University of the South Pacific}

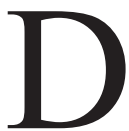

IGITAL democracy' and 'digital government' (or 'e-democracy'/ 'e-government' or 'cyber democracy'/'cyber government') have become fashionable new topics of debate in political education and media circles. Digital democracy is argued to increase participation in the political process. ${ }^{2}$ In contrast, digital government may increase citizens' access to information about their government (policies and processes) therefore increasing transparency and contributing to political education. This depends on several variables including access and interest. It also depends 
on the type of technology being used by governments. Pacific Island states are increasing their internet presence. However, to date, it can be argued that the technological capabilities in some countries tend to be more compatible with digital government than digital democracy.

If digital democracy does not yet exist in Pacific Island countries, then what has been the contribution of Pacific government web-presence to democracy? As a form of digital government, to what degree has the medium of communication enhanced political education within a state? A third question for consideration is if the advent of the digitalisation of the political process and political education has eliminated the role of more 'traditional' media in the form of newspapers, television and radio within the region?

The way in which such questions can be addressed, academically and practically, depends on the field or discipline they are being raised in. The answers given are also likely to be dependent on such considerations. The question of the use of media (whether new or old) as a tool of education should not be limited to the media alone, particularly as in some circles, the legitimacy of mass media as an educator may be questioned. This article is written from a political science perspective. ${ }^{3}$ In political science circles, such debate is also likely to give rise to questions of the legitimacy of media (either traditional or new) as an effective political educator (generally arguing that many mediums are constrained by various challenges that do not allow for indepth analysis or research). This article has been written to meet a gap in literature in both disciplines, recognising that a more multidisciplinary perspective is required when trying to answer some of the questions posed.

To place the research within some of the contemporary literature, it should be noted that this discussion is not intended to subscribe to either a 'cyber pessimist' or 'cyber optimist' view of the role of the internet and its impact on political participation or education within the region (Norris, 2000; Barber, 1998). Nor is this contribution interested in adding to any of the theoretical and philosophical debate emerging. Rather, it is intended to raise some pertinent questions about the current status and assess potential implications of using digital technology as part of the democratic process in Pacific Island countries.

While arguing that, as a result of current capabilities and developments, new media cannot replace traditional media as a tool for political education, the development of materials available on the internet must be recognised as 
a key resource for journalists, students, researchers and educators in the field of politics and government in Pacific Island countries, particularly those who live outside of the 12 selected countries which have access to the material. This in itself is a key point. Much of the material available is of benefit to those who live outside of the selected countries. Traditional media-in the form of radio, print and (to a lesser extent) television journalism and public advertisement - is still essential for the political education of the population as a whole.

\section{Inbox or ballot box? Setting the parameters}

Digital democracy and digital government, in all of their guises, are relatively new terms in the political science lexicon. They are also rather ambiguous concepts that need definition before their use can be analysed. For the purpose of this article, Digital Democracy, at its simplest, can be understood to refer to the use of certain technologies by individuals to participate in the democratic process. However, such a definition still requires further deconstruction.

What is crucial here is the separation of the two terms. 'Digital', 'electronic' or 'cyber' refers to the mode of delivery. In general use, it is not restricted to the internet alone (although this may be a common perception) but can extend to other forms of technology as well (such as the mobile phone) (Barber, 1998; Norris, 2000). However, the focus here is on the internet as a mode of delivery for enhancing political participation and political education.

While the definition of the 'digital' component of this concept is relatively straightforward, more difficult to define is democracy. It may seem trivial to dwell on such an issue but it is worthwhile for establishing the context. In the selected Pacific Island countries, democracy tends to conform to a parliamentary model. That is, it is generally indirect and representative. This form of democracy is very different to the direct mode because it already preconditions the type of political participation local populations are likely to engage in. Barber has referred to this type of democracy as 'passive', arguing that, in such a system

Experts and elites ...do the actual work of government, while citizens remain watchdogs and monitors, primarily engaged in private lives and private affairs. (Barber, 1998) 
It is this distinction between 'elites' and 'citizens' that will be revisited at a later stage because the notion of electing an elite class of people to govern is pertinent to ideals of democracy in the Pacific as it is often portrayed as an egalitarian equaliser vis-à-vis traditional hierarchies. As such, democracy has come to mean many things in the selected Pacific Island countries. While the processes and structures are different in each country, there are some commonalities. Democracy in these countries currently requires eligible citizens to vote for a representative in their parliament (or legislative assembly) on a regular basis. In most instances, the decision to cast the vote is voluntary while in others (such as Fiji and Nauru) it is compulsory. Citizens are not compelled to actively participate in the political process in any other way although they may choose to do so. For example, membership in civil society groups (non-government organisations, trade unions, professional organisations, clubs, societies and religious institutions, for example) may determine the way in which they engage in public, and ultimately 'political' life. Political participation, as such, is not necessarily direct.

As with digital democracy and digital government, other concepts are worthy of definition. Political participation is often viewed as a healthy part of democracy. But participatory democracy is a variable form of democracy. Democracy itself does not compel people, by their membership of a state, to be involved in the political process explicitly. Political education-characterised in this paper primarily as akin to civics education-is also not compulsory. While it is useful in a democracy for members of a country to have a good understanding of the structures, processes, and mechanisms of government to make political choices, it is not part of the criteria for eligibility to vote in any of the selected countries. In some understandings of civics education, it is the responsibility of the citizen to become 'educated' about the functions, purpose, and issues. The question of exactly who should be responsible for educating the public on these matters-the governors or the governed-is still open to debate.

\section{Political and civics education: The role of the media}

In light of recent political challenges in many of the selected countries, questions have been raised about the effectiveness of political or civic education in the region. Questions abound about the type of systems present in the Pacific, if local people understand the electoral system, and what the level 
of knowledge is regarding constitutional and political processes. To this end, government and civil society actors (predominately in the form of NGOs) have been involved in the education process. Often, this has been through more traditional forms of communication-radio and newspaper advertisements or statements, plus training/workshops.

The media, as an important civil society actor, has a specific role to play in the process of political education. First, by reporting on key issues and events, journalists can keep people up to date with changes in government. The media is involved in reporting on the processes and any transgressions that may happen. Much of the role of the media in a democratic society is about governance - the way in which a democratic state runs-rather than government. Accordingly, it is fair to say that in terms of electronic media and democracy, the emphasis should be more on the monitoring or watchdog capacity of the media as it applies to governance rather than on government.

The media-in conjunction with other parts of civil society-has a specific role to play as a mediator rather than monitor (Norris, 2000, p. 1). In this view, the role of media as a crucial part of the democratic process is explicit. Accordingly, the ensuing argument is that both digital government and digital democracy can contribute to a more direct form of democracy. The first, by creating more avenues for citizens to acquire information, the latter opening up avenues for voting online and offering citizens a new method of communicating with their government (Norris, 2000). The type of digitalisation of government services and information that has occurred so far within the Pacific region is more compatible with digital government than participatory digital democracy as it arguably encourages a more passive relationship with democracy and political processes.

In a democracy, media is able to involve the people in the process of politics to some degree. Radio talk back shows (and television talk back shows such as Fiji One's Have Your Say) and newspaper 'letters to the editor' sections enable citizens and non-citizens to air their views regarding the political status and processes of a country.

This type of engagement with the political process (and with political leaders) can be seen as an adjunct rather than a deliberate component. That individuals are allowed to have their say publicly can be considered one fraction of the democratic equation entirely dependent on how one views democracy. The internet, as part of new media, is allowing people to have 
another mode of communication with their leaders and other members of the public. Many newspapers with web presences have online forums and conduct online polling. While of potential interest for members of the public, politicians and government members alike, this may be considered more part of the human rights equation (in terms of freedom of speech) than contributing to democratic processes within a country.

\section{Pacific government online}

The majority of selected countries have varying degrees of an internet 'presence'. Four of the selected country's parliaments-Fiji, Samoa, Solomon Islands and Tonga ${ }^{4}$ —all have their own dedicated websites. Fiji's includes Hansard transcripts of meetings of the House of Representatives and Senate as well as Bills. Tonga's website includes information about the committees, the way in which the Fale Alea works and its members. The Parliament of Samoa website includes similar information. Solomon Islands Parliament's new website is comprehensive. It includes Hansard, information about the Parliament and the roles and functions of various officers.

The central or national governments of Cook Islands, Fiji, Niue, Samoa, Tonga and Vanuatu all have an internet presence, ${ }^{5}$ as does Marshall Islands (through the Office of the President) ${ }^{6}$ and Solomon Islands (through the Office of the Prime Minister and Cabinet). ${ }^{7}$ Tonga has an additional site through the Office of the Prime Minister. ${ }^{8}$ For the most part these websites include information such as the organisational structures of government, the history of the legislatives and executive, press releases and news stories. Fiji's is arguably the most comprehensive but Tonga, with two separate sites, also offers a wealth of information.

The Council for Ongoing Government in Tokelau has a website. ${ }^{9}$ The website includes information on the way in which Tokelau is currently governed, the status of the referendum for self-determination, copies of important government agreements and a bulletin board of important events. The government of Tuvalu has a presence but the legitimacy is currently difficult to gauge. ${ }^{10}$ Kiribati and Nauru do not yet have dedicated government websites (or if they do, they were not easily located).

Internet presence is not limited to official central government websites. A bevy of ministries and departments also have their own websites some of which reflect current interests of the government or the state. Key issues 
include tourism, ${ }^{11}$ finance or investment, ${ }^{12}$ and environment. ${ }^{13}$ To a lesser degree issues such as culture, ${ }^{14}$ education ${ }^{15}$ and health ${ }^{16}$ can also be seeing as pressing areas worthy of web attention by some governments.

The level of government web presence for the selected countries varies. Some countries have given a considerable amount of effort in digitalising the information about their work. Cook Islands and Fiji are the two countries with the most significant web presence. In some instances, as in the case of Fiji, the amount of information available on the internet regarding the work of various ministries and departments is overwhelming.

In addition to those areas already mentioned in this article, another two Cook Islands entities have a presence on the internet (the Statistics Office and the Ministry of Works), ${ }^{17}$ and almost all of Fiji's Ministries and government departments have some degree of web information. Fiji's Ministry of Information ${ }^{18}$, Ministry of Foreign Affairs, ${ }^{19}$ Ministry of Youth, Employment Opportunities, Sports and Productivity, ${ }^{20}$ Ministry of Women, Social Welfare and Housing ${ }^{21}$ and the Ministry of Agriculture, Fisheries and Forests ${ }^{22}$ all have their own dedicated websites outlining the work that they do. The Ministry of Labour, Industrial Relations, Tourism and Environment has two, ${ }^{23} 24$ as does the Ministry of Lands and Natural Resources. ${ }^{25}{ }^{26}$ At the time of writing this article, the Public Service Commission website was still under construction. ${ }^{27}$ The Ministry of Commerce, Industry, Investment and Communications does not have a dedicated website to the work of the ministry but it does maintain the National Trade Measurements and Weights website. ${ }^{28}$ In addition various departments, such as the Department of Immigration, ${ }^{29}$ Department of Energy and Rural Electrification, Department of Bureau of Statistics, Elections Department, Prisons Department, and Meteorology also have their own websites. The type of information on such government websites ranges from press releases to organisational structures to photo galleries of recent activities.

In some instances, government websites are maintained by associated offices. For example, Nauru's Permanent Mission to the United Nations has a website which includes a raft of information ranging from the various international treaties Nauru is party to, to its diplomatic relations, to information about tourism in Nauru. ${ }^{30}$ The Republic of Marshall Islands Embassy to the United States website is another example of a comprehensive virtual 'onestop shop' of information about the country. It includes financial year reports,

100 PACIFIC JOURNALISM REVIEW 13 (2) 2007 
information about various social issues (eg. health, education, environment) and, again, information for those wishing to travel to the state. ${ }^{31}$

\section{Is internet use enhancing political participation and education?}

While enthusiasts of the internet point to it as a valuable contributor to political education and participation, ${ }^{32}$ an assessment of the value it is adding still needs to be made. It can be argued that all of the information provided on the government specific websites contributes to transparency. In many instances, it contributes to the political education of the reader. Materials related to political or civic education are readily available on the internet. The constitutions of all eleven independent countries are available online ${ }^{33}$, as is the draft constitution for Tokelau. ${ }^{34}$ Information about human rights conventions states are a party to and the full text of such agreements can be accessed through a variety of United Nations websites. Countless reports and research papers from academics, donor agencies, foreign governments, regional and international organisations are all available through the internet.

However, at this juncture, it is essential to ask several questions about the way this is contributing to political education and participation. On the participation front, the websites do not encourage participation actively, but rather subliminally. The more information people have, it can be argued, the more 'educated' their choices will be. Knowing and understanding the role and function of various members of government and offices, as well as having a good understanding of the processes should, theoretically, contribute to more effective participation in the democratic process. Regarding education, there are still many pertinent questions to be asked. Is this internet presence serving to educate all of the people about the role and function of government? Who exactly is it serving to educate?

In the absence of specific surveys undertaken, it is necessary to rely on some 'educated guesses' or assumptions. Those using the service will be those who have access to it and those who have an interest. In the selected countries the implications of these key assumptions do not bode well for the internet as a contributor to political participation or education.

\section{Inhibiting factors and challenges}

Without undermining the impressive efforts of Pacific Island governments to make this information available to the public, it must be acknowledged 
that there are a number of inhibitive factors. Such challenges are noteworthy if digital government and digital democracy are ever to become relevant to Pacific Island populations.

\section{Availability of technology and access}

Generally in the selected countries, access to internet technology is still quite limited. This is partially related to the technological capacity as well as a range of other factors that are outside of the parameters of discussion in this article. UNESCO (2003) conducted a survey on the use of technology in education in Asian and Pacific countries. The results are relevant to this brief study.

At the time the survey was conducted, in the Cook Islands the internet was generally available in three centers (Rarotonga, Aitutaki, and Mangaia). In Fiji, access to the internet was generally restricted to the capital and accessible to a fairly limited degree. Kiribati, Marshall Islands, Nauru, Samoa, and Solomon Islands all reported varying degrees of access and capability but, for the most part, access could not be considered 'universal'. Tonga's internet capability is mainly concentrated on the main island of Tongatapu. In Tuvalu, the internet is available in the capital but general public access is somewhat limited (UNESCO, 2003).

Another survey, undertaken as part of a regional workshop on the use of information and communication technologies (ICT) in education in Pacific Island countries (hosted by the University of the South Pacific in 2005), revealed similar results. In Kiribati, accessibility was largely restricted by cost and the 'limited connections available' (USP, 2005, p. 34). In the Marshall Islands, infrastructural factors were pointed to as an inhibiting factor which restricted the technology to the major centers of Majuro and Ebeye. But even in these centers, infrastructure and environmental challenges were joint concerns affecting the resource. Infrastructural issues were also a concern in Nauru, Tonga, Vanuatu, Niue, Cook Islands, Tuvalu, Kiribati and Samoa (USP, 2005).

\section{Cost}

In almost all of the selected countries, the high cost of internet access (at home, in schools, in the work place or in public internet cafes) has been pointed to as an inhibiting factor. There are several reasons for the high cost 
including the current status of technological developments and the monopolies that some companies have over telecommunications in some countries (USP, 2005).

In Niue, the country with the largest number of users (as shown below) the cost has been offset by the establishment of the Internet Users Society which is able to provide internet to the Niuean people at no cost (Saint Clair). The free service is not without some limitations (commercial interests and a certain amount of use as well as some infrastructural challenges), but the high user rates in Niue in comparison to other selected countries show how prohibitive economic related matters are.

\section{Literacy issues}

When dealing with the concepts of digital government and digital democracy as contributors to political education, there are multiple literacy issues that need to be addressed. On of the most obvious ones is language. For the most part, the various government websites are produced in the English language. This raises issues about language as a barrier. The Council for Ongoing Government in Tokelau site offers users the choice of language (Tokelaun or English). Other government sites do not although some include local language text. In countries where English is a second or third language, this may prove to be an inhibiting factor.

Another literacy issue is related to computer and internet literacy (Jacobs, n.d; Barber, 1998). Not everyone has access to computer training through the school system. Not all have used the internet before. This can prove to be a barrier to effective use of the tool. Jacobs has noted that much of the training in new media is taught on a 'self-education' basis. In the selected Pacific Island countries, computer studies and other forms of ICT education (including internet) are being integrated into some of the formal school curriculums but there are still challenges in infrastructure, cost and delivery (USP).

A third literacy issue is one raised by Barber (1998) and that is the matter of research literacy. Just because the information is available should not infer that people will become 'educated'. How to discern a valid or reliable website of information from a not so valid one can be difficult for many. What information should people be accessing for their political education? Is all information useful? Or is some of it unnecessary? 
Determining the validity or reliability of websites is difficult for novice users and researchers. The internet can be considered a valuable tool for researchers but it is one that must be used in conjunction with other tools (including knowledge of the topic being researched) to be truly valuable.

\section{Interest}

Making information available by new modes of technology will not necessarily dictate that the public is any more likely to access it or be interested. Jacobs (n.d.) cites a study conducted in the United States in 1997 that noted users of internet government sites were those specifically interested in political information. They typically 'represent a form of avant garde of on-line political participators. Moreover, this group visits government and politicsoriented web sites, and they are highly engaged in political affairs traditionally'. ${ }^{35}$ That is to say, the people that are interested in accessing such sites tend to be quite political in their outlook and interest.To cultivate an interest in political and government issues, more than digital advances need to be taken into consideration. A shift in curriculum at the primary and secondary school level and further recognition of the value of relevant subjects may also be required. In this regard, our culture of political education and attitudes towards politics in general must be considered. As Barber (1998) has noted:

Technology has entailments and tendencies, but on the whole, history shows that it more generally reflects and mirrors the culture in which it evolves rather than guiding and directing it.

The ensuing argument here is that if our 'political culture' does not make a sound political education necessary for participation in the process then the internet technology may be somewhat redundant. The potential of utilising the internet for political purposes (including education) is almost limitless but if individuals are not interested in the subject then the effort and expense may be futile.

\section{Technology usage}

The amount of access to the internet must also be addressed in terms of usage. While there are currently no definitive statistics available information is available (ironically through the internet) which makes it possible to estimate 
the percentage of users in each country. The CIA's World Factbook contains information on population estimates as well as the type of technology available in each country and the number of internet users. This information can only be considered to be a crude approximation because many significant changes have occurred over the last five years in technology capabilities and resources. However, using these statistics, the percentage of users throughout the Pacific Island region is variable and ranges from approximately 60 percent of the population in Niue $^{36}$ to just over 16.5 percent in the Cook Islands, ${ }^{37}$ almost 11 percent in Tuvalu, ${ }^{38}$ and 7 percent in Fiji. ${ }^{39}$ For the other selected countries the percentage of population using the internet is all well under 5 percent. ${ }^{40}$ While this statistical information is not without difficulties, it can still be argued that the majority of populations in most of the selected countries do not have access to the internet for one reason or another. This must raise serious questions about the degree to which the internet can and should be used as a tool for enhancing political participation or education.

\section{Inclusive or exclusive participation}

Government and associated websites can be best understood as part of e-government (digital government). That is, as information providers, they do not overtly invite the general public to interact or participate in the process of government. However, by providing information about the role and function of government, their ministries and various bodies, it does contribute to political education for a certain audience.

Internet media invites more participation. By allowing public forums and online voting, it opens up the gateways and enables people to have their say and participate in the process. 'Virtual Community' websites often invite users to contribute to the website and often people do use the forums to comment or debate on issues of current political interest. ${ }^{41}$ Some forums are even specifically related to government and politics (such as the Government and Politics forum on the Planet Tonga website). ${ }^{42}$ But this is an informal avenue, in much the same vein as letters to the editor sections of newspapers. The degree to which debate can be open is limited as websites rely on a moderator who monitors and sometimes edits postings to the site. Some virtual community websites participate actively in the political process. For example, in the 2006 general elections in Fiji, a Rotuma community website invited candidates for the Rotuman communal seat to post their CVs and party manifestos on the 
website. ${ }^{43}$ As already suggested earlier in the article, the level to which such interaction is contributing to political processes or education is through the opening of a new mode of communication, not the creation of a more democratic environment.

However, it is still worth asking that, in these more 'participatory' websites, who is having their say? Who is participating? According to Jacobs (n.d.), 'political participation online is as yet the practice of a highly educated elite'. While a clear generalisation, if the majority of people living in the selected Pacific Island countries do not have access to the resources (irrespective of the reason) then the chances of them being able to participate are slim.

When reviewing the question of who is accessing the website information or forums, it may also be worthwhile asking who is meant to be accessing the technology? As with all media, there must be an audience in mind. Pacific Island governments well understand the limitations faced by their populations in terms of accessing the internet. If we assume that the materials are only for those people who have access to the internet, then, in light of the limitations on access discussed in this article, this does not auger well for political education in general. Nor will it translate into an increase in political participation across the board. If, on the other hand, we assume that the information is not intended for local populations who face restrictions on their access then the following assumption is that the materials must be for overseas audiences. Is this the case? Are Pacific Island governments investing in a web presence to satisfy the international community (whether it be aid donors, international organisations or citizens living abroad)? The political implications of this, and the type of democracies potentially being created should be of concern. In either context, it would appear that a more elite form of democracy-where information is channeled only to the privileged few-is the objective rather than a more egalitarian democracy.

\section{Conclusion}

With the current status of technology accessibility in the region in general a 'back to basics' approach for political education and participation may still be the most conducive to an egalitarian rather than elitist democracy. Traditional forms of media, such as radio and newspaper are still among the most reliable for Pacific populations. In terms of using media for the political education of the Pacific Island public, from a perspective of communicating 
with the entire population in general, these are still the means that should be advocated. This is not to say that digital technologies are redundant. But a realistic view is needed about the way in which the use of such technology can assist rather than transform political education and participation. Internet technology can be considered as only part of the equation.

At this point, it may be worth recalling one of the basic tenets of democracy: Democracy_in all its forms-essentially relates to the majority. Until the majority have access to the information and technology then the viability of digital democracy in Pacific Island states must be questioned. Pacific Island governments have a need to explore internet (and other) forms of technology. If these new forms of media can assist with the political education of people and make participation in the political process more meaningful then they are indeed valuable. But, in the interests of egalitarian participatory democracy, Pacific governments need to ensure that all of their people have equal access to education and participation. Until then, this may be a luxury needing reconsideration.

\section{Notes}

1. Cook Islands, Fiji, Kiribati, Marshall Islands, Nauru, Niue, Solomon Islands, Samoa, Tokelau, Tonga, Tuvalu, and Vanuatu

2. 'E-democracy', Wikipedia. Retrieved on 21 August 2007 from: (www.wikipedia. org/wiki/E-democracy)

3. Gratitude must be extended to the anonymous reviewers for feedback on this article, and particularly for comments drawing attention to the readership of the journal.

4. Respectively available online as Parliament of Fiji Islands website www. parliament.gov.fj; Website for the Parliament of Samoa (www.parliament.gov. ws); National Parliament of the Solomon Islands website (www.parliament.gov.sb); Parliament of Tonga website (parliament.gov.to).

5. Cook Islands Government Online website (www.cook-islands.gov.ck); Fiji Government Online Portal website (www.fiji.gov.fj); Government of Niue website (www.gov.nu); (www.govt.ws); (www.gov.to); Government of the Republic of Vanuatu website (www.vanuatugovernment.gov.vu)

6. Office of the President Republic of Marshall Islands website (www.rmigovernment. org/index.jsp)

7. Department of Prime Minister and Cabinet website (www.pmc.gov.sb)

8. The official website of the Government of the Kingdom of Tonga (pmo.gov.to)

9. Council of Ongoing Government (www.tokelau.org.nz)

10. Mape O Tuvalu (map.tuvalu.tv) 
11. Tuvalu's Ministry of Finance, Economic Planning and Industries has a website devoted to tourism in Tuvalu (see www.timelesstuvalu.com); Vanuatu's National Tourism Office has a website (www.vanuatutourism.com); as does the Cook Islands Tourism Corporation (see www.cook-islands.com); Niue's Tourism Office (www. niueisland.com) and Samoa's Tourism Authority (see www.visitsamoa.ws). One of Fiji's Ministry of Labour, Industrial Relations, Tourism and Environment's two websites focuses on tourism (see www.tourism.gov.fj)

12. Vanuatu has placed priority on such sites. The Financial Services Commission has a dedicated website (see www.vfsc.vu/cms/) and Vanuatu's Investment Promotion Authority maintains a site which includes information such as the Government's National Investment Policy (Vanuatu Government (2005) National Investment Policy, March (www.investinvanuatu.com/images/policy.pdf); Niue Companies Office has its own website (www.companies.gov.nu/cms); Cook Islands has a range of sites dedicated to financial matters. Examples include sites developed by the Development Investment Board (see www.cookislands-invest.com/ipa_default.asp), Financial Intelligent Unit (see www.cifiu.com), Audit Office www.auditoffice.gov. ck; as well as the Ministry of Finance and Economic Management (www.mfem. gov.ck); . Fiji's government also has a raft of websites focusing on environment or investment matters. Ministry of Finance and National Planning (www.mfnp.gov.fj)

13. Given the environmental challenges facing the region, it is perhaps of little surprise that a number of websites are dedicated to environment information and monitoring. Some sites are hosted by other agencies. For example, Niue's Meteorological Service has a web presence through the South Pacific Regional Environment Programme's (SPREP) Pacific Island Global Climate Observing System (see www.pi-gcos.org/ niuesite/default.htm). In contrast, the Cook Islands' National Environment Service has developed its own website (www.environment.org.ck).

14. The governments of Cook Islands and Fiji are two that have given attention to such issues. Cook Islands Ministry of Cultural Development (www.culture.gov.ck). The Ministry of Fijian Affairs, Heritage, Provincial Development, and Multiethnic Affairs has three sites dedicated to different areas, relevant to broad cultural issues (see www.culture.gov.fj, www.fijianaffairs.gov.fj, and www.multiethnicaffairs.gov. fj).

15. Again, the governments of Cook Islands and Fiji are two that have given attention to such issues. See Ministry of Education Cook Islands website www.education.gov. ck and Republic of Fiji Islands Ministry of education website www.education.gov.fj. 16. The Cook Islands Ministry of Health and Fiji's Ministry of Health maintain websites. See MOH Cook Islands Ministry of Health website www.health.gov. ck and Shaping Fiji's Health: Official website of Ministry of Health - Fiji (www. health.gov.fj)

17. See Cook Islands Statistic Office (www.stats.gov.ck) and Ministry of Works (www.mow.gov.ck/tiki/tiki-index.php).

18. Ministry of Information (www.info.gov.fj)

19. The Republic of Fiji Islands Ministry of Foreign Affairs and External Trade (www.foreignaffairs.gov.fj) 
20. Ministry of Youth, Sports, Employment Opportunities and Productivity (www.youth.gov.fj)

21. Women, Social Welfare and Housing (www.women.fiji.gov.fj)

22. Ministry of Agriculture, Fisheries and Forests (www.agriculture.org.fj)

23. Ministry of Tourism (www.tourism.gov.fj)

24. Ministry of Labour and Industrial Relations (www.labour.gov.fj)

25. Republic of Fiji Islands Department of Lands and Surveys (www.lands.gov.fj)

26. Mining and Geology in Fiji website (www.mrd.gov.fj/gfiji/)

27. Public Service Commission (www.psc.gov.fj)

28. www.weights.gov.fj

29. Fiji Immigration Department (www.immigration.gov.fj); Department of Energy (www.fdoe.gov.fj); Fiji Islands Bureau of Statistics (www.statsfiji.gov.fj); Elections 2006: Fiji Islands (www.elections.gov.fj); Fiji Prisons \& Corrections Services (www.corrections.org.fj; Fiji Meteorological Service www.met.gov.fj) 30. Permanent Mission of the Republic of Nauru to the United Nations (www.un.int/nauru/)

31. Embassy of the Republic of the Marshall Islands, Washington DC (www.rmiembassyus.org)

32. A key example is Norris.

33. One very good website is Pacific Islands Legal Information Institute-Pacific Law (PacLII). (See the website www.paclii.org).

34. Tokelau Constitution, as reproduced on the Council of Ongoing Government website (www.tokelau.org.nz/selfdeter/constitution.html)

35. Jacobs cites the following article by Bruce Bimber; The internet and political communication in the 1996 election season. (www.sscf.ucsb.edu/ survey1/index. html)

36. Based on a usage rate of 900 people in 2002 and the current population estimate. See CIA (n.d.) 'Niue', World Factbook, (available online) (https://www.cia.gov/ library/publications/the-world-factbook/geos/ne.html)

37. Based on a usage rate of 3600 users in 2002 and the current population estimate. See CIA (n.d.) 'Cook Islands', World Factbook, (available online) (https://www.cia. gov/library/publications/the-world-factbook/geos/cw.html\#Comm)

38. Based on a usage rate of 1300 users in 2002 and the current population estimate. See CIA (nd) 'Tuvalu', World Factbook, (available online) (https://www.cia.gov/ library/publications/the-world-factbook/geos/tv.html\#Comm).

39. Based on a usage rate of 61,000 users in 2004 and the current population estimate. See CIA (n.d.) 'Fiji', World Factbook, (available online) (https://www.cia. gov/library/publications/the-world-factbook/geos/fj.html\#Com).

40. In the Marshall Islands, the figure is about 3.2 percent (based on 2000 internet users in 2005 and current population estimates. See CIA (nd) 'Marshall Islands', World Factbook, (see https://www.cia.gov/library/publications/the-world-factbook/ geos/rm.html ) In Nauru approximately 2.2 percent of the population has used the internet (based on 300 users in 2002 and the current population estimate. See CIA (nd) 'Nauru', World Factbook, (available online) (https//www.cia.gov/library/ 
publications/the-world-factbook/geos/nr.html). In Samoa the percentage of users is about 2.79 percent (based on 6000 users in 2004 and current population estimate. See CIA (nd) 'Samoa', World Factbook, (available online) (https://www.cia.gov/ library/publications/the-world-factbook/geos/ws.htm). For Solomon Islands the number of users is approximately 1.5 percent of the population (based on 8500 users and current population estimates. See CIA (n.d.) 'Solomon Islands', World Factbook, (available online) (https://www.cia.gov/library/publications/the-worldfactbook/geos/bp.html). In Tonga the percentage is approximately 2.5 percent (Based on a usage rate of 3000 in 2004 and the current population estimate. See CIA (nd) 'Tonga', World Factbook, (available online) (https://www.cia.gov/library/ publications/the-world-factbook/geos/tn.html). In Vanuatu approximately 3.5 percent of the population was using the service. (Based on a usage rate of 7500 in 2004 and the current population estimate. See CIA (nd) 'Vanuatu', World Factbook, (available online) (https://www.cia.gov/library/publications/the-world-factbook/ geos/nh.html). In Kiribati the figure is 1.85 percent. (Based on a usage rate of 2000 in 2004 and the current population estimate. See CIA (n.d.) 'Kiribati', World Factbook, (available online) (https://www.cia.gov/library/publications/the-worldfactbook $/ \mathrm{geos} / \mathrm{kr}$.html).

41. For example, the Yokwe website has a forum discussion on the 2007 elections for Marshall Islands (see www.yokwe.net/index.php?module=pnForum\&func= viewforum\&forum=35). The Noa'ia 'e Mauri Rotuma website has a number of politics related forums (see www.rotuma.net/os/Forum/Forum1.html). The Pipol Faestem website has a public forum which includes issues of relevance to politics and government (see www.peoplefirst.net.sb/message_board/outline_forum.asp)

42. Planet Tonga website http://forums.planet-tonga.com/viewforum.php?f=19\&s $\mathrm{id}=60 \mathrm{bbe} 78 \mathrm{c} 45 \mathrm{~d} 959 \mathrm{f} 6 \mathrm{ef} 5663 \mathrm{e} 62 \mathrm{~d} 11860 \mathrm{~d} 43$. These are still available on the site. See, Noa'ia 'e Mauri Rotuma website, Election 2006 page (www.rotuma.net/os/ NewsArchive/Archive2006/election2006.htm).

\section{References}

Barber, B. (1998). Which technology and which democracy?, Media in Transition website, University of Massachusetts. Retrieved on 22 August 2007 from: http://web.mit.edu/m-i-t/articles/index_barber.html

CIA. (2007). The world factbook. Retrieved on 23 August 2007 from: www.cia. gov/library/publications/the-world-factbook/

Internet Niue User Agreement (2002, June 7). As reproduced on the Internet Users Society Niue website. Retrieved on 23 August 2007 from: www.niue.nu/iusn/ terms.htm?

Jacobs, J. (n. d.). Democracy and the internet. Article reproduced on The Good Citizen: Australian Democracy and Citizenship website, Australian Broadcasting 
Corporation Retrieved on 22 August 2007 from: http://abc.net.au/ola/citizen/interdemoc/democ.htm

Norris, P. (2000). Theories of digital divide. In Norris, P. (2001), Digital divide: civic engagement, information poverty, and the internet worldwide. Cambridge: Cambridge University Press. Retrieved on 21 August 2007 from: http://ksghome.harvard.edu/ pnorris/acrobat/digitalch5.pdf

UNESCO (2003). Meta-survey on the use of technologies in education in Asia and the Pacific 2003-2004. Edited by G. Farrell and C. Wachholz. Bangkok: UNESCO Asia and Pacific Regional Bureau for Education.

USP (2005). ICT in secondary education in the Pacific region: status, trends and prospects. Edited by the ICT Capacity Building at USP Project. Suva, Fiji: ICT Capacity Building at USP Project, University of the South Pacific. Retrieved on 22 August 2007 from: www.usp.ac.fj/jica/ict_research/documents/pdf_files/ICT\% 20in $\% 20$ Secondary $\% 20$ Education $\% 20$ in $\% 20$ the $\% 20$ Pacific\%20Region.pdf Yokwe website. www.yokwe.net

Kylie Anderson is a lecturer in politics in the School of Social Sciences of the University of the South Pacific. She is coordinator of the 100, 200 and 400 level Pacific Island politics and international affairs courses.

anderson_k@usp.ac.fj 